\title{
IMPACT OF DRIVERS FOR THE IMPLEMENTATION OF GREEN CONCEPT IN SMALL AND MEDIUM SIZED (SMES) LEATHER INDUSTRIES OF NORTHERN TAMILNADU
}

\author{
G. Kathiresan ${ }^{1, *}$ and S. Ragunathan ${ }^{2}$ \\ ${ }^{1}$ Department of Mechanical Engineering, SSM College of Engineering, Komarapalayam, \\ Namakkal District-638183, Tamilnadu, India. \\ ${ }^{2}$ Department of Mechanical Engineering, AVS Engineering College, Military Road, Ammapet, \\ Salem District-636006, Tamilnadu, India. \\ *E-mail: kathirmechengg1980@gmail.com
}

\begin{abstract}
The eco-friendly structure of supply chain concentrates on the accountability of an organization in valuing the entire ecological effects of yields through its complete life cycle, from the procurement of raw materials to the final utilization and products disposal. This paper aims to delineate the pressures for espousing greenness in supply chain management among small and medium sized leather industries of northern Tamilnadu. Drivers which aid to implement Green Supply Chain Management are defined via literature review and also from leather industry experts. The quantitative figures were evaluated using regression analysis, correlation and standard deviation. The outcomes of this analysis exposed that a management commitment, green procurement and green marketing methodologies, eco-friendly proposal and environ praxis are not contemplated by the industries to green the entire supply chain (SC) system. Even though the environmental protocols and policies of leather industries are rigorous, the industries are violating the rules because there is no action from concerned boards. This work proposes concerned departments to formulate apt monitoring structure and consolidative supply chain philosophy to restraint the problems and to support balanced economic growth.
\end{abstract}

Keyword: Supply Chain, Leather Industries, Standard Deviation, Procurement, Greenness, Regression, Emissions.

(c) RASĀYAN. All rights reserved

\section{INTRODUCTION}

With the globalization of financial system, the supply chain has become an auspicious space in attaining viability due to international ecological duress and the notion of "green supply chain management (GSCM)". The management of the supply chain is an imperative component that can assist businesses to inferior their environmental and social costs ${ }^{1}$. In order to sustain in the competitive global market, to attain the equipoise of cost reduction, financial growth, and eco-friendship, most of the multinational firms have established networks of their providers globally to surge their competitiveness. As such, an increasing number of Tamilnadu industries are persistently observing at rampant techniques to improve their supply chain structures for the purpose of increasing productivity and refining environmental performance. Most of the companies have grasped their liabilities and commenced executing several ecofriendly practices like cleaner production, implementation of ISO accreditation etc. to encounter their ecological goals. Moreover, manufacturing industries in India are promoting 'green practices'. It supports the surrounding atmosphere. Of course, it also assists the metier. Nowadays organizations in India are pressurized to follow greenness in their process, as many of their Western counterparts are constructing ecological sustainability into their organization practices. Every flourishing initiation of the green formation may provide novel ways to estimate core trade plans ${ }^{2}$. Hence, most of the industries have taken a step forward to green their core function. Environment Management System (EMS) assists the companies to promote ecological performance, only within the firm's operation confines in precedence of through the supply chain ${ }^{3}$. While implementing the supply chain management system ${ }^{4}$; industries should give major attention towards the customer demeanour ${ }^{5}$. 
RASĀYAN J. Chem.

Vol. 10 | No. 3 |723 - 728 | July - September | 2017

\section{Literature Review}

GSCM can be detached into introspective -industrial ecological procedures; erstwhile interprets the forms of mediocre vague resources and the later refers to communally multifaceted resources ${ }^{6}$. Intra-industrial environ policies, such as high-quality environmental management and offal management systems are focused on vigor utilization, material ingestion, discharges and waste in association with innate methods. On the contrast, for organizations, the interrogation of how to organize introspective management procedures that stimulate pervasive worker participation and incessant learning is vital to dropping and precluding pollution. Inter-industrial ecological policies, such as contrivance for the environment, analysis of life cycle, green diffusion and reverse logistics are usually designated to as product work plans $^{7}$ which accentuate coalitions between vendors and customers to reciprocally deal with crossbusiness environmental disputes ${ }^{8}$. These methods furnish a collaborative platform between SC partners, and thus inaugurate societal linkages entrenched with faith and dedication which inspire knowledge exchange and reciprocity?.

As a result, inter-firm environmental policies have socially multifarious characteristics and trust on intimate co-operation between companies and supply chain comrades ${ }^{10}$. These methods also pressurize the prominence of fetching opposite steps to efficiently incorporate vendors and customers ${ }^{11}$. Supply chain amalgamation characterizes cooperation among supply chain comrades in both intra- and inter-firm practices. The elucidations of the authors designate that green supply chain incorporation is the association of an industry and its supply chain cohorts to direct both intra- and introspective organizational environmental methods. To this end, Green Supply Chain aids to evaluate, analyze and meliorate the performance among numerous affiliates to certify that industries are functioning in an ecofriendly manner or not.

In order to provide a more comprehensive depiction of the challenges, they are detached into internal and external ones. As internal drivers are significant for the adoption of green notions, but these do not overtly refer to introspective organizational supply chain procedures. Even though internal hurdles do not fit to the preface of green supply chain management bluntly, they are of pivotal for the triumph of such systems. Hence, it is vital to grasp what troubles might occur and the necessity to be taken care of in order to swear active support on an introspective organizational basis. Basically, the investigation of external hurdles illustrates that the key trouble is based on the fact that globally acting firms are antagonized with diverse protocols and environmental acts in the various countries. This can obstruct reforming an international supply chain.

Barriers for implementation of GSCM comprehends: lack of technology advancement; deficiency in organization motivation; lack of skilled human resources; wrangler and uncertainty in market; paucity of government funds and support ; dearth in executing green practices; scarcity of management onus; cost effects; vendor reluctance to transit towards GSCM and ignorance of customers ${ }^{12}$.

The fiscal performance is not being procured in short-term lucrative and sales performance when GSCM methods are enforced ${ }^{13}$. The literary texts over the decades seem to have alienated sights on whether there are combined gains, "win-win's", or trade-offs that must be handled for environmental and economic performance in viable supply chains ${ }^{14}$. Among barricades to execute environ management practices; the acutest facet seems to be economic grounds and disputes allied to costs ${ }^{15}$. Constraints to organizations' demeanor may arise from the enactment of core techniques as well as from conformity with extant environmental protocols. Ecological-control such as compliances with internal and external techniques postulates substantial boundaries to the opportunistic behavior of companies as well as increased functional costs, and this may not benefit the fiscal performance of the contributing industries ${ }^{16}$. These assorted results in the relationships between economic and environmental performance guides to some possibilities of more complex negotiations occurring between core and outward practices.

\section{Problem Description}

It is vivid from the literature that ample exploration has been in the arena of GSCM. It is miserable that Indian industrialized sector is not yet espousing the notion of GSCM strongly. It is a renowned fact that leather industries play an imperative role next to yarn and fabric industries in the northern part of 
Tamilnadu. Leather industries in Tamilnadu are getting reformed hastily but are still reluctant to accept the concept of GSCM. The emission caused by the tanning industries lead to creating extreme pollution to the environment. According to the statement of PCB (Pollution control Board) authorities, leather industry segment secured bad score in the green grading program, and supply chain has an enormous impact in dropping the green rating of the industry. So it is vital to pinpoint the drivers which motivate the industries to transpose from formal supply chain to an enviro-friendly supply chain and also help the organizations to attain GSCM system ${ }^{17}$.

\section{Conceptual Framework}

Based on the exploration queries and assumption, the theoretical framework insists on the consequence of firm commitment, eco-friendly design, and green supply chain methods (like green procurement, green Manufacturing, green marketing, green distribution) on environmental, social and fiscal performances ${ }^{18}$.

\section{Research Queries}

1. What does the existing plight of GSCM practices in leather industries?

2. How do leather industries meet awareness of external stakeholders' face to face builds of the green supply chain?

3. What is the outcome of GSCM perceptions on firm efficiency?

4. What are challenges of adopting GSCM?

\section{Assumption}

Organizational commitment, green purchasing, green marketing, investment recovery, eco-friendly design, environmental practice will not surely affect social, economic, environmental performance ${ }^{18}$.

\section{EXPERIMENTAL}

To discourse what is imputed by the exploration, triangulation illustrative technique was employed. To answer the exploratory questions both quantitative and qualitative facts were used together. Therefore, descriptive exploration design was used to examine Northern Tamilnadu leather industries performances. This work comprises administrator of leather industries, industrial department and pollution control board as a population for Analysis. From the leather industry database of northern Tamilnadu, fifteen leather industries were identified.

An attentively structured set of queries were framed which mired all tricky aspects which would assist the possibility of a change of the conventional supply chain method to green supply chain method. The designed questionnaires were sent to leather industry authorities (i.e., managers) and were exhaustively briefed to rank the drivers in a five-point scale method ${ }^{19}$. Based on the gathered response, numerous methods were adopted (like mean, standard deviation, correlational and regression methods) to analyze the information.

The grade points are tabulated below:

Table-1: Grade Points and its Remarks

\begin{tabular}{c|c|l}
\hline S. No. & Grade Points & Remarks \\
\hline 1 & 3.5 to 5.0 & Fully Considerable Variable \\
\hline 2 & 2.0 to 3.4 & Currently Considerable Variable \\
\hline 3 & 1.0 to 2.0 & Unconsidered Variable \\
\hline
\end{tabular}

\section{RESULTS AND DISCUSSIONS}

A detailed analysis was carried out. Based upon the analysis their respective mean, standard deviation values were found and its remarks were discussed in the following tables. 
RASĀYAN $J$. Chem.

Vol. 10 | No. 3 |723 - 728 | July - September | 2017

Table-2: Effects related to Organizational Commitment

\begin{tabular}{c|l|c|c|l}
\hline S. No. & \multicolumn{1}{|c|}{ Criteria } & Mean & Std. Deviation & \multicolumn{1}{|c}{ Discussion of Results } \\
\hline 1 & Top Management Commitment & 3.49 & 0.83 & $\begin{array}{l}\text { Result shows that the top } \\
\text { management commitment } \\
\text { towards greening the entire } \\
\text { supply chain is significant }\end{array}$ \\
\hline 2 & $\begin{array}{l}\text { Cross-functional Teams to Minimize } \\
\text { environmental impacts }\end{array}$ & 3.55 & 0.81 & $\begin{array}{l}\text { Result shows the existence of } \\
\text { cooperation among cross } \\
\text { functional teams }\end{array}$ \\
\hline 3 & $\begin{array}{l}\text { Performance on green initiative } \\
\text { effects, employee evaluation \& } \\
\text { compensation }\end{array}$ & 3.18 & 0.83 & $\begin{array}{l}\text { Reveals that different opinions } \\
\text { among employees and indicate } \\
\text { more training and awareness } \\
\text { needed and }\end{array}$ \\
\hline $\begin{array}{l}\text { Environmental Management Systems } \\
\text { EMS) }\end{array}$ & 3.33 & 0.76 & $\begin{array}{l}\text { Result shows that the leather } \\
\text { industries are considering the } \\
\text { green concept to improve the } \\
\text { environment management }\end{array}$ \\
\hline
\end{tabular}

Table-3: Eco-Design related issues

\begin{tabular}{|c|c|c|c|c|}
\hline S. No. & Criteria & Mean & Std. Deviation & Discussion of Results \\
\hline 1 & $\begin{array}{l}\text { Products designed for Energy } \\
\text { Consumption }\end{array}$ & 2.70 & 1.30 & $\begin{array}{l}\text { The result shows that while } \\
\text { designing the product, leather } \\
\text { industries are consuming low } \\
\text { material and low energy. }\end{array}$ \\
\hline 2 & $\begin{array}{l}\text { Products designed for Reuse, and } \\
\text { Recycle }\end{array}$ & 2.13 & 0.98 & $\begin{array}{l}\text { Result reveals that recycling was } \\
\text { taken into consideration by few } \\
\text { leather industries }\end{array}$ \\
\hline 3 & $\begin{array}{l}\text { Design of products to sustain } \\
\text { ecological framework }\end{array}$ & 2.75 & 1.26 & $\begin{array}{l}\text { The obtained value implies that } \\
\text { Industries are avoiding the usage } \\
\text { of toxic and hazardous materials } \\
\text { during the product design to } \\
\text { enhance eco-friendly } \\
\text { environment }\end{array}$ \\
\hline
\end{tabular}

Table-4: Green Procuring and Marketing related issues

\begin{tabular}{|c|c|c|c|c|}
\hline S. No. & Criteria & Mean & Std. Deviation & Discussion of Results \\
\hline 1 & $\begin{array}{l}\text { Supplier Cooperation } \\
\text { environment objectives }\end{array}$ & 2.0 & 0.96 & \multirow{3}{*}{$\begin{array}{l}\text { The result shows that industries } \\
\text { are planning to ruminate green } \\
\text { procuring in greening the entire } \\
\text { supply chain. }\end{array}$} \\
\hline 2 & Environmental Auditing & 2.07 & 1.08 & \\
\hline 3 & Vendors ISO 14000 Certification & 1.88 & 0.93 & \\
\hline 4 & $\begin{array}{l}\text { Customer Cooperation for Eco-Design } \\
\text { and low energy consumption }\end{array}$ & 1.75 & 1.18 & \multirow{2}{*}{$\begin{array}{l}\text { Result reveals that industries are } \\
\text { planning to cogitate the green } \\
\text { marketing as a distinctive } \\
\text { component of GSCM in future. } \\
\text { It also shows that industries are } \\
\text { forced to transpose thei } \\
\text { conventional system into Eco } \\
\text { friendly system due to customer } \\
\text { awareness. }\end{array}$} \\
\hline 5 & $\begin{array}{l}\text { Customers Cooperation for green } \\
\text { packaging }\end{array}$ & 1.70 & 1.17 & \\
\hline
\end{tabular}


RASĀYAN J. Chem.

Vol. 10 | No. 3 |723 - 728 | July - September | 2017

Table-5: Environmental Performance outcome

\begin{tabular}{|c|c|c|c|c|}
\hline S. No. & Criteria & Mean & Std. Deviation & Discussion of Results \\
\hline 1 & Diminution of Air emission & 2.75 & 1.09 & \multirow{5}{*}{$\begin{array}{l}\text { Results exhibit that organizations } \\
\text { have a certain level of interest in } \\
\text { reducing all mentioned criteria. }\end{array}$} \\
\hline 2 & Wastewater Reduction & 3.02 & 0.41 & \\
\hline 3 & Cut-back of solid wastes & 3.27 & 0.63 & \\
\hline 4 & Down-Sizing of accidents & 3.36 & 0.77 & \\
\hline 5 & Material Recycle & 3.40 & 0.87 & \\
\hline
\end{tabular}

Table-6: Economic Performance outcome

\begin{tabular}{|c|c|c|c|c|}
\hline S. No. & Criteria & Mean & Std. Deviation & Discussion of Results \\
\hline 1 & Energy consumption cost reduction & 2.72 & 1.59 & \multirow{4}{*}{$\begin{array}{l}\text { Results imply that the firms have } \\
\text { a certain level of keenness in } \\
\text { cost reduction to meet economic } \\
\text { performance. }\end{array}$} \\
\hline 2 & $\begin{array}{l}\text { Reduction in materials purchasing } \\
\text { cost }\end{array}$ & 3.08 & 1.21 & \\
\hline 3 & Offal treatment fee reduction & 3.07 & 1.06 & \\
\hline 4 & $\begin{array}{l}\text { Improvement in overall Environmental } \\
\text { Situation. }\end{array}$ & 3.49 & 0.99 & \\
\hline
\end{tabular}

Table-7: Social Performance outcome

\begin{tabular}{c|l|c|c|l}
\hline S. No. & \multicolumn{1}{|c|}{ Criteria } & Mean & Std. Deviation & Discussion of Results \\
\hline 1 & Professional Ethics & 3.99 & 0.75 & Unremarkable \\
\hline 2 & Involvement in Social works & 3.90 & 0.67 & Remarkable \\
\hline 3 & Creating Job opportunities & 3.72 & 1.07 & Remarkable \\
\hline 4 & Adheres to government law & 2.0 & 1.59 & Insignificant \\
\hline
\end{tabular}

\section{CONCLUSION}

Theoretical research on GSCM for leather industries is still in the evolving stage. This paper provides an effort to inspect the GSCM framework in Small and Medium sized (SMEs) leather industries of northern Tamilnadu. A petite research has been conducted in small and medium sized leather industries of Northern Tamilnadu. The results of this study are able to pinpoint the pressures for implementing GSCM practices on Small and Medium Sized leather industries by analyzing the drivers using a questionnaire surve $^{20}$. As per outcome of this paper, it is observed that, stakeholder's cooperation (SHC) is the vital criterion and has peerless emphatic power for the enactment of green supply chain system in Tamilnadu Leather Industries. It was also found that cost effects, deficiency in trained manpower reserves, and impedance to technology development adoption are rated as crucial challenges in executing green supply chain management. Moreover, respondents stated customer's ignorance, the reluctance of vendor to transit towards GSCM, lack of government funds and policies are also stated as challenges in executing green supply chain management in Tamilnadu leather industries.

\section{REFERENCES}

1. I.Wycherley, International. Business Strategy and the Environment, 8, 120(1999).

2. K.W.Hansmann and K.Claudia, 2001, Environmental Management Policies, in: Sarkis, J. (Ed.), Green Manufacturing and Operations: from Design to Delivery and Back, Greenleaf Publishing, Sheffield, pp. 192-204.

3. R.Handfield, R.Sroufe and S.Walton, Business Strategy and the Environment, 14, 1(2004).

4. Semih Coskun, Leyla Ozgur, Olcay Polat and Asiner Gungor, Journal of Cleaner Production, 110, 149(2016). 
RASĀYAN J. Chem.

Vol. 10 | No. 3 |723 - 728 | July - September | 2017

5. Sini Laari, Jusso Toyli, Tomi Solakivi and Lauri Ojala, Journal of Cleaner Production, 112, 1960(2016).

6. T.Wu, Y.C. Jim Wu, Y.J.Chen, and M.Goh, International Journal of Production Economics (In Press). http://dx.doi.org/10.1016/j.ijpe.2013.

7. S.Vachon and R.D.Klassen, International Journal of Operations \& Production Management, 26(7), 795(2006).

8. C.W.Y. Wong, K.H. Lai, K.C. Shang, C.S. Lu and T.K.P. Leung, International Journal of Production Economics, 140, 283(2012).

9. S.L.Hart, Academy of Management Review, 20(4), 986(1995).

10. Shi, Han Jinping Tian and Lujun Chen, J. Ind. Ecol., 16(3), 290(2012).

11. B.B.Flynn, S. Sakakibara, R.G.Schroeder, K.Bates and J.Flynn, Journal of Operations Management 9(2), 250(1990).

12. Sunil Luthra, L.Vinod Kumar, Sanjay Kumar and Abid Haleem, Journal of Industrial Engineering and Management, 4(2), 231(2010).

13. F.E.Bowen, P.D. Cousins, R.C. Lamming and A.C. Faruk, Greener Management International Autumn, 41(2001).

14. S.Seuring and M.Mu“ller, Journal of Cleaner Production, 16(15), 1699(2008).

15. S.Ambec and P.Lanoie, When and why does it pay to be green? (Discussion Paper No. IEA-07-04). Montreal: HEC. Available at http://www.hec.ca/iea/cahiers/2007/iea0704_planoie.pdf Accessed on October 3, 2014(2008).

16. Henri, Jean Francois and Marc Journault, Accounting, Organizations and Society, 35, 63(2010).

17. G.Kathiresan and S.Ragunathan, Advances in Natural and Applied Sciences, 10(15), 31(2016).

18. Zellalem Tadesse Beyene, International Research Journal of Engineering and Technology, 02(07), 587(2015).

19. G.Kathiresan and S.Ragunathan, Advances in Natural and Applied Sciences, 10(16), 103(2016).

20. Xiangmeng Huang, Boon Leing and Dong Li, International Business and Management, 4(1), 76(2012).

[RJC-1754/2017] 